\title{
Responsabilidade civil na mineração: o caso Samarco
}

Fábio Santos ${ }^{1}$

Fagner Gomes ${ }^{2}$

Resumo: Este estudo de caso vem discutir a responsabilidade civil na mineração: o caso da Samarco, que gerou o maior acidente ambiental dos últimos tempos no Brasil, de repercussão internacional. Buscou responder como, apesar das especificações e rigor das leis, desastres e danos irreversíveis ainda são causados pelos empreendedores do setor extrativista mineral, prejudicando o meio ambiente. Com os objetivos de identificar os aspectos gerais da responsabilidade civil e penal com relação à exploração de minério no Brasil, foi apresentado o caso da Samarco, responsável pela maior tragédia ambiental local. Assim, foi verificada a aplicabilidade da lei vigente à extração mineral, geradora de danos, o nível de comprometimento do agente explorador com o meio extraído, enfatizando a responsabilidade socioambiental, por meio de uma pesquisa documental, o que embasou a discussão realizada com o propósito de se averiguar os desdobramentos processuais da questão. Pode-se concluir que tal discussão gerará muitos debates e embates nos âmbitos municipal, estadual e federal, pois os responsáveis pelo acidente causador de danos e impactos negativos na localidade fazem uso de todos os recursos possíveis, utilizando-se da prerrogativa que a lei lhe faculta, para protelar o cumprimento de suas obrigações de reparo e recompensa aos prejudicados.

Palavras-chave: Legislação. Meio Ambiente. Mineração. Responsabilidade civil. Samarco.

Abstract: This case study discusses civil liability in mining: the case of Samarco, which generated the largest environmental accident of recent times in Brazil, with international repercussions. It sought to answer how, despite the specifications and rigor of the laws, disasters and irreversible damages are still caused by the entrepreneurs of the extractive mineral sector, harming the environment. With the objective of identifying the general aspects of civil and criminal responsibility for the exploitation of ore in Brazil, the case of Samarco, responsible for the greatest local environmental tragedy, was presented. Thus, it was verified the applicability of the current law to the mineral extraction, generating damage, the level of commitment of the exploring agent with the extracted medium, emphasizing the socio-environmental responsibility, through a documentary research, which supported the discussion held for the purpose To ascertain the procedural developments of the matter. It can be concluded that such discussion will generate many debates and conflicts at the municipal, state and federal levels, since those responsible for the accident causing damages and negative impacts in the locality makes use of all the resources that the same law assigns to him to delay the fulfillment Of their obligations to repair and reward those harmed.

Keywords: Civil responsability. Environment. Legislation. Mining. Samarco.

\footnotetext{
${ }^{1}$ Graduado em Direito pela Universidade Estadual de Santa Cruz (UESC). Especialista em Direito Público e em Docência do Ensino Superior. Mestre e Doutorando em Desenvolvimento Regional e Urbano pela Universidade Salvador (UNIFACS). Professor da Faculdade de Tecnologia e Ciências (FTC), campus Itabuna. E-mail: fabiosantosdireito@gmail.com.

${ }^{2}$ Graduado em Direito pela Faculdade de Tecnologia e Ciências (FTC), campus Itabuna. E-mail: fagner1985@hotmail.com
}

Página 247 Caderno de Ciências Sociais Aplicadas, Vitória da Conquista/BA, vol. 14, n 24, ano 14, p. 247-265, jul/dez 2017. 


\section{Introdução}

O desenvolvimento humano e econômico das sociedades contemporâneas está condicionado diretamente pela produção de riquezas, muitas destas encontradas no meio natural, do qual todos os biomas existentes dependem e do qual precisam para se perpetuarem sobre a terra.

O extrativismo, seja vegetal ou mineral, exige da natureza uma demanda de recursos que a mesma já não vem suportando ao longo de séculos de exploração, cujo desgaste de suas propriedades, através do uso de materiais e recursos degradantes, como os produtos químicos, gera consequências graves e por vezes irreversíveis ao meio ambiente.

$\mathrm{Na}$ história recente do Brasil, uma grande tragédia ecológica deu-se em consequência do extrativismo mineral, na cidade de Mariana, estado de Minas Gerais, com mortes e prejuízos de ordem material para os moradores, e irreversíveis (até o presente momento) para a natureza, com a poluição de rios, mortandade e extinção da vida aquática presente e da produção agrícola local.

A legislação em vigor referente à defesa, proteção e conservação dos recursos naturais, disposta na Lei no 6.938, de 31 de agosto de 1981, que dispõe sobre a Política Nacional do Meio Ambiente, abriu caminho para a criação de resoluções e decretos, artigos e mais incisos que vieram a impor aos empresários do setor condições e regras rígidas para a execução de atividade exploratória, cuja responsabilidade com o meio ambiente só ganhou força nas últimas décadas.

Tratando-se de responsabilidade socioambiental, depois da tragédia em Mariana (MG), a sociedade tem cobrado de legisladores, executores e exploradores mais compromisso, seriedade, transparência e legitimidade nas ações e relações com a comunidade oriunda dos locais de exploração, com o apoio e vigilância da imprensa, fazendo com que haja menos danos ao meio natural.

Apesar das leis vigentes, muito de atroz ainda se faz quando se trata da exploração ou extração de recursos naturais necessários à produção de produtos (bens de consumo), que também é geradora de postos de trabalho. A exploração mineral, amplamente discutida na mídia global no último ano, levanta a questão da responsabilidade ambiental na mineração que, embora seja apontada, discutida e mostrada como imprescindível para a conservação da vida e dos próprios recursos, conduz esta pesquisa tendo em vista a ampliação da perspectiva de pesquisadores, acadêmicos, legisladores e da própria sociedade, vindo a justificar sua realização.

Assim, o presente estudo busca identificar os aspectos gerais da responsabilidade civil com relação à exploração de minério no Brasil, conhecendo o caso da Samarco, responsável pela maior

Página 248 Caderno de Ciências Sociais Aplicadas, Vitória da Conquista/BA, vol. 14, n 24, ano 14, p. 247-265, jul/dez 2017. 
tragédia ambiental no Brasil; verificando a aplicabilidade da lei vigente à extração mineral, geradora de danos.

\section{Meio Ambiente e Mineração}

De necessidade fundamental para a vida humana, o meio ambiente interage em um conjunto de elementos naturais, artificiais e culturais, propiciando um desenvolvimento equilibrado da vida em todas as suas formas (SILVA, 1994).

O artigo $3^{\circ}$. da Constituição Federal de 1988, define Meio Ambiente como sendo o conjunto de condições, leis, influências e interações de ordem física, química e biológica, que permite, abriga e rege a vida em todas as suas formas. Esse conjunto de elementos, tão importantes e necessários para a existência da vida, vem sendo colocado à prova em todo momento, desde o início dos tempos. A contemporaneidade impôs ao homem a necessidade do consumo e por meio deste o mercado extraiu em demasia do meio natural, fornecedor único e soberano de todos os insumos para a manutenção da vida de todos os seres viventes.

Assim sendo, o meio ambiente, conjunto de vida para a permanência da vida, é o bem mais precioso dos seres viventes, do qual se tira muito e para o qual pouco tem se olhado com responsabilidade, respeito e comprometimento em preservar para que haja sustentabilidade e reserva de recursos.

As questões ambientais ocupam cada vez mais espaço entre as preocupações das sociedades democráticas de todo o planeta. Infelizmente, os debates parecem motivados antes por ameaças, crises e catástrofes ecológicas pontuais do que por uma conscientização espontânea da importância estratégica de conciliar desenvolvimento socioeconômico com sustentabilidade.

Percegona (2016) afirma que a situação do meio ambiente obriga a sociedade a preservar os recursos naturais e, também, a fazer com que haja um desenvolvimento social justo, para que assim, ela consiga ter uma melhor qualidade de vida, em todos os sentidos. Nesse sentido, salienta a autora que, verbis, "Precisa-se buscar alternativas de utilização de recursos, que se oriente por uma racionalidade ambiental e por uma ética de solidariedade, para que se possa consolidar um novo modelo de desenvolvimento sustentável”.

O meio ambiente sofreu diversas mudanças devido à influência do homem, embora, durante séculos, o homem tenha conseguido viver em harmonia com a natureza, conquanto tudo que ele

Página 249 Caderno de Ciências Sociais Aplicadas, Vitória da Conquista/BA, vol. 14, n 24, ano 14, p. 247-265, jul/dez 2017. 
retirava e devolvia para o meio ambiente, não fazia com que seu equilíbrio natural se alterasse (PERCEGONA, 2016).

A descoberta do Brasil não despertou em Portugal, nas primeiras décadas que a seguiram, qualquer grande interesse exploratório. A pequena e grande nação ibérica estava mais interessada no desenvolvimento de seus canais comerciais que abasteciam a Europa com produtos orientais, as especiarias (SILVA, 2009).

A transferência da Corte Portuguesa para o Rio de Janeiro, em 1808, permitiu que D. João VI, então Príncipe Regente, tomasse conhecimento da inexorável decadência da mineração de ouro e de diamantes e procurasse recuperá-las. Foi, então, contratado pela coroa portuguesa o Barão Wilhelm Ludwig Von Eschwege, formado na Universidade Göttingen, na Alemanha. O Barão von Eschwege chegou ao Brasil em 1810 com a missão de diagnosticar o estado da mineração brasileira e encaminharlhe soluções práticas e modernas para sua recuperação, assim como avaliar outros recursos minerais ainda não explorados, sugerindo formas de aproveitamento (SILVA, 2009).

Enquanto se lavraram as ocorrências das diversas substâncias minerais encontradas na superfície do solo brasileiro nos primórdios da colonização, as massas retiradas eram sempre muito pequenas e adotavam-se métodos rudimentares na sua extração. Por outro lado, as necessidades de produtos de origem mineral eram, naquele tempo, ainda muito pequenas. As argilas, areia e cascalho para construções constituíam a principal demanda (GERMANY, 2002).

De acordo com as pesquisas de Germany (2002), as ferramentas utilizadas para a extração desses materiais eram rudimentares e pouco resistentes, feitas normalmente de ferro caldeado. Até o século XIX, era também muitíssimo pequena a produção do ferro no Brasil, existindo apenas algumas forjas catalãs em Minas Gerais.

Era bastante tímido o desenvolvimento tecnológico que ocorria na extração das rochas para os trabalhos de cantaria, a fim de atender aos artífices trazidos pelos colonizadores. Os diversos materiais de construção eram principalmente retirados dos aluviões e, quando de afloramentos rochosos, eram cuidadosamente desagregados com cunhas, acompanhando-se as clivagens e amarroados ou cortados com ponteiros e marretas e, quando necessário, perfurados e detonados com pólvoras caseiras. Ainda se encontram, hoje em dia em Diamantina, Ouro Preto e outras cidades históricas, construções e calçamentos com lajes de rocha retiradas de pedreiras desta maneira (GERMANY, 2002).

A situação se modificou, segundo os estudos de Silva (2009), quando foram encontrados os ricos aluviões auríferos de Minas Gerais, já no século XVII, onde o pouco conhecimento da arte da 
mineração era compensado pela riqueza do jazimento e facilidade de extração do metal, liberado e grosseiro. Além disso, escravos trazidos de regiões africanas frequentadas por árabes conheciam princípios de mineração aprendidos com esses povos. Esta foi certamente a primeira importação de tecnologia da mineração brasileira.

A atividade de mineração do chamado "Ciclo Econômico do Ouro" que se sobrepõe também à descoberta e extração de diamantes (século XVII), caracterizou-se por ações predatórias dos jazimentos, agressão violenta ao meio ambiente, imprevidente desequilíbrio que causava desabastecimento e, consequentemente, ciclos de fome que castigavam os pioneiros da mineração. As autoridades, como sempre, estavam ausentes nas funções de encaminhar soluções aos problemas, mas muito presentes na cobrança do quinto e na manutenção de seus privilégios corporativistas (SILVA, 2009).

A mineração é um dos setores básicos da economia do país, contribuindo de forma decisiva para o bem estar e a melhoria da qualidade de vida das presentes e futuras gerações, sendo fundamental para o desenvolvimento de uma sociedade equânime, desde que seja operada com responsabilidade social, estando sempre presentes os preceitos do desenvolvimento sustentável (FARIAS, 2002).

$\mathrm{Na}$ Conferência Rio+10, realizada de 26 de maio a 29 de agosto de 2002, em Johanesburgo, em várias partes de seu documento final, assinado por todos os países presentes, a mineração foi considerada como uma atividade fundamental para o desenvolvimento econômico e social de muitos países, tendo em vista que os minerais são essenciais para a vida moderna.

Importante destacar que o subsolo brasileiro possui importantes depósitos minerais. Parte dessas reservas são consideradas expressivas quando relacionadas mundialmente. O Brasil produz cerca de 70 substâncias, sendo 21 do grupo de minerais metálicos, 45 dos não-metálicos e quatro dos energéticos. Em termos de participação no mercado mundial em 2000, ressalta-se a posição do nióbio (92\%), minério de ferro (20\%, segundo maior produtor mundial), tantalita (22\%), manganês (19\%), alumínio e amianto (11\%), grafita (19\%), magnesita (9\%), caulim (8\%) e, ainda, rochas ornamentais, talco e vermiculita, com cerca de 5\% (BARRETO, 2001).

O perfil do setor mineral brasileiro é composto por 95\% de pequenas e médias minerações. Segundo a Revista Minérios \& Minerales, 1999, os dados obtidos nas concessões de lavra demonstram que as minas no Brasil estão distribuídas regionalmente com 4\% no norte, $8 \%$ no centro-oeste, 13\% no nordeste, $21 \%$ no sul e 54\% no sudeste. Estima-se que em 1992 existiam em torno de 16.528 pequenas

Página 251 Caderno de Ciências Sociais Aplicadas, Vitória da Conquista/BA, vol. 14, n 24, ano 14, p. 247-265, jul/dez 2017. 
empresas, com produção mineral de US $\$ 1,98$ bilhões, em geral atuando em regiões metropolitanas na extração de material para construção civil. (BARRETO, 2001).

Assim como ocorreu no período colonial, a maior parte dos bens minerais extraída no País em pleno século XXI abastece o mercado externo. O setor mineral 79vem conquistando mais espaço na base econômica nacional. No $1^{\circ}$ semestre de 2013, o valor da produção mineral brasileira (VPM) foi de $\mathrm{R} \$ 32,5$ bilhões, e a produção anual chegou a R \$ 95 bilhões de dólares, segundo o Instituto Brasileiro de Mineração (IBRAM). O setor mineral no Brasil é dominado por algumas poucas empresas e possui uma característica oligopolista, onde as 10 principais empresas do setor possuem 63,6\% do valor total da produção comercializada (em 2009) (GUEDES, 2015).

No Brasil, a mineração, de um modo geral, está submetida a um conjunto de regulamentações, onde os três níveis de poder estatal possuem atribuições com relação à mineração e o meio ambiente.

Segundo o Guia do Minerador (2000) a legislação infraconstitucional que disciplina a matéria ambiental relativa à atividade de mineração, está consubstanciada basicamente nos seguintes diplomas legais, resoluções e portarias:

- Leis Federais:

* Lei n ${ }^{\circ}$ 6.938, de 31 de agosto de 1981 e suas alterações (Leis n n $^{\circ} .804$, de 18 de julho de 1989, e 8.028, de 12 de abril de 1990) - Dispõe sobre a Política Nacional do Meio Ambiente, seus fins e mecanismos de formulação e aplicação;

* Lei n ${ }^{\circ}$ 9.537, de 11 de dezembro de 1997 - Dispõe sobre a segurança do tráfego aquaviário em águas sob jurisdição nacional e que atribui à Autoridade Marítima estabelecer normas sobre obras, dragagem, pesquisa e lavra mineral sob, sobre e às margens das águas jurisdicionais brasileiras.

* Lei $n^{\circ}$ 9.605, de 12 de fevereiro de 1998, sobre os Crimes Ambientais, dispõe sobre as sanções penais e administrativas derivadas de condutas e atividades lesivas ao meio ambiente, e dá outras providências.

- Decretos Federais:

* Decreto no 97.632 de 10 de abril de 1989 - Dispõe sobre Plano de recuperação de área degradada pela mineração; Decreto no 99.274 de 6 de junho de 1990 Regulamenta a Lei no 6.938, de 31 de agosto de 1981.

* Resoluções do Conselho Nacional do Meio Ambiente - CONAMA Resolução do CONAMA n 1 , de 23 de janeiro de 1986 - Estabelece critérios básicos e diretrizes gerais para o Relatório de Impacto Ambiental (RIMA);

Página 252 Caderno de Ciências Sociais Aplicadas, Vitória da Conquista/BA, vol. 14, n 24, ano 14, p. 247-265, jul/dez 2017. 
* Resolução do CONAMA nº 009 de 6 de dezembro de 1990 - Dispõe sobre normas específicas para a obtenção da licença ambiental para a extração de minerais, exceto as de emprego imediato na construção civil.

* Resolução do CONAMA n 010 de 6 de dezembro de 1990 - Dispõe sobre o estabelecimento de critérios específicos para a extração de substâncias minerais de emprego imediato na construção civil.

* Resolução do CONAMA n 2 de 18 de abril de 1996 - Dispõe sobre a compensação de danos ambientais causados por empreendimentos de relevante impacto ambiental; Resolução do CONAMA n 237 de 19 de dezembro de 1997 - Dispõe sobre os procedimentos e critérios utilizados no licenciamento ambiental.

* Resolução do CONAMA n 303 de 20 de março de 2002 - Dispõe sobre parâmetros, definições e limites de áreas de Preservação Permanente.

Resolução do Conselho Nacional de Recursos Hídricos - CNRH no 16 de 8 de maio de 2001 Estabelece critérios gerais para a outorga de direito de uso de recursos hídricos.

Está em estudo no CNRH, em sua oitava versão, resolução que estabelece as diretrizes para a outorga de uso dos recursos hídricos para o aproveitamento dos recursos minerais.

O Estudo de Impacto Ambiental (EIA), que é exigido para o licenciamento ambiental de qualquer atividade de aproveitamento de recursos minerais e dele se distingue, tem sua definição, normas e critérios básicos, e diretrizes de implementação estabelecidos pela Resolução do CONAMA $\mathrm{n}^{\mathrm{o}} 1 / 86$.

\section{Responsabilidade civil na mineração}

No âmbito do Direito Civil, a responsabilidade civil decorre da prática de um ato ilícito lato sensu, que pode derivar-se do descumprimento de um contrato, do descumprimento de uma declaração unilateral de vontade ou da prática de atos intrinsicamente ilícitos, na medida em que causam danos a terceiros (LARCHER, 2012).

Gonçalves (2003, p. 07) ensina que "Responsabilidade civil é, assim, um dever jurídico sucessivo que surge para recompor o dano decorrente da violação de um dever jurídico originário".

Assim sendo, a responsabilidade civil faz inerente a todos, visto que a maioridade associada à plenitude das faculdades mentais faz de qualquer cidadão um ser responsável por seus atos, tanto para o

Página 253 Caderno de Ciências Sociais Aplicadas, Vitória da Conquista/BA, vol. 14, n 24, ano 14, p. 247-265, jul/dez 2017. 
bem ou para mal, legais ou ilegais, levando-se à reflexão e constante debate sobre os grandes acontecimentos que impactam as comunidades, principalmente quando os danos são grandiosos, catastróficos e dolosos.

Conforme cita Larcher (2012), segundo o artigo 186 do Código Civil Brasileiro, in verbis, “ato ilícito é toda ação ou omissão voluntária, negligente ou imprudente que viola direito e causa dano a outrem" (BRASIL, 2002, online), o dispositivo legal evidencia os elementos do ato ilícito ensejador da responsabilidade civil, concernentes ao dever de indenizar, a saber, antijuridicidade, culpabilidade, dano e nexo causal. O direito civil brasileiro, com raras exceções, adota a teoria subjetiva da responsabilidade civil, por que está baseada na culpa do agente.

A adoção do modelo subjetivo de responsabilidade civil (calcado na noção de culpa) tem por fundamento o "valor da vontade como fonte última de qualquer obrigação" (COELHO, F. U., 2012, p. 225). No mesmo sentido, entende Pereira (2014, p. 524) que "o fundamento maior da responsabilidade civil está na culpa". A responsabilidade civil é dita "subjetiva" porque tem como foco o sujeito, isto é, a vontade do sujeito, que agiu de determinada maneira, quando poderia ter se comportado de outra e evitado, assim, a ocorrência do dano. Funda-se, portanto, na autonomia da vontade.

É clássica a lição de Dias (1994, p.1), segundo a qual "toda manifestação da atividade humana traz em si o problema da responsabilidade", que pode ser definida, no campo jurídico, como um dever jurídico sucessivo, surgido para recompor o dano provocado pela violação de um dever jurídico originário (CAVALIERI FILHO, 2010, p.2).

Com os desdobramentos de mais estudos sobre a matéria, surgiram, assim, outras teorias fundamentadoras da responsabilidade civil, com vistas a indicar um fundamento que, além de explicar a razão de ser da responsabilidade, fosse consentâneo com a sua finalidade-mor de recomposição de danos.

Com base nesse novo modelo, a ênfase na responsabilização passou a dar-se no dano, e não mais no sujeito. Havendo dano, o seu causador deve repará-lo, ainda que não tenha agido com culpa, cuja existência ou não passa a ser irrelevante. Daí por que essa espécie de responsabilidade é dita “objetiva”, em contraposição à subjetiva, baseada na culpa do sujeito.

A principal teoria surgida para respaldar o movimento pela objetivação da responsabilidade civil foi a teoria do risco, cujos precursores foram os juristas franceses Raymond Saleilles e Louis Josserand (DIAS, 1994, p. 57). Segundo essa teoria, todo aquele que exerce uma atividade deve arcar com o risco de dano que essa atividade potencialmente oferece a terceiros, caso ele venha a se concretizar.

Página 254 Caderno de Ciências Sociais Aplicadas, Vitória da Conquista/BA, vol. 14, nº 24, ano 14, p. 247-265, jul/dez 2017. 
Necessário observar que normalmente os argumentos contrários à tese da responsabilização penal da pessoa jurídica se prendem a questões de ordem puramente dogmática, com ressalto às inspirações individualistas sob as quais nasceram os princípios do garantismo penal e os conceitos jurídico-penais clássicos. Busca-se, a partir das concepções pré-definidas no campo doutrinário, a conformação das alterações propostas pelo legislador, em um movimento inverso ao que normalmente deveria ocorrer, ou seja, a adequação da doutrina à lei (ALVES, 2009, p. 15).

O relevante papel exercido pela Pessoa Jurídica na organização social, somado à realidade dos crimes econômicos e ambientais, com a participação cada vez maior desses entes coletivos para a sua efetivação, tem suscitado a discussão sobre a amplitude da responsabilidade da Pessoa Jurídica (SAKAE, 2004).

$\mathrm{Na}$ questão ambiental, a responsabilidade civil da pessoa jurídica se baseia na teoria do risco da atividade. Assim, independente de culpa, o exercício de atividade, com ou sem fins lucrativos, mesmo que não perigosa, mas que venha a provocar dano ao meio ambiente, é fundamento para a reparação dos prejuízos causados, desde que provado o nexo de causalidade (SAKAE, 2004).

Nesta esfera, trata-se da responsabilidade da pessoa jurídica frente ao poder público, "fruto da supremacia do interesse público sobre o privado, destacando-se nesse ponto a necessidade de o transgressor ser responsabilizado pelo custo social do Estado na proteção do meio ambiente" (RODRIGUES, 2002, p.187).

Doutrinariamente, não se questiona se a pessoa jurídica pode ser sujeito dessa infração, bastando que esteja em desacordo com os preceitos regulamentares, para sofrer as consequências de sua irregularidade (SAKAE, 2004).

As infrações administrativas podem ocorrer tanto pela "conduta omissiva" como pela "comissiva", uma vez que a legislação ambiental além de impor um padrão de comportamento, uma obrigação positiva (de fazer), pode exigir uma prestação negativa, de não praticar determinados atos que podem vir a prejudicar o meio ambiente.

No tocante "à gravidade” da perturbação causada, Rodrigues (2002) divide as infrações administrativas em "materiais ou formais"; verificando-se a primeira, quando se observar um dano efetivo, e, a segunda, quando se constituir mera infração a dispositivo legal.

Há que se registrar que, no sistema jurídico brasileiro, a ocorrência de um dano ambiental em razão do exercício de uma atividade econômica, ainda que autorizada, e, portanto, lícita, gera para o empreendedor o dever de reparar o dano ou indenizar (LARCHER, 2012).

Página 255 Caderno de Ciências Sociais Aplicadas, Vitória da Conquista/BA, vol. 14, nº 24, ano 14, p. 247-265, jul/dez 2017. 
Isto porque a responsabilidade civil por danos causados ao meio ambiente é objetiva, ou seja, não depende de culpa do agente, nos termos do que dispõe o artigo 225 , $\mathbb{S 3 ^ { \circ }}$, da Constituição Federal de 1988:

Art. $225-[\ldots] \int 3^{\circ}$. As condutas e atividades consideradas lesivas ao meio ambiente sujeitarão os infratores, pessoas físicas ou jurídicas, a sanções penais e administrativas, independentemente da obrigação de reparar os danos causados (BRASIL, 1988, online).

No mesmo diapasão, o artigo 14, \$1º da Lei 6938/1981 (Política Nacional do Meio Ambiente):

Art. $14-[\ldots] \rrbracket 1^{\circ}$. Sem obstar a aplicação das penalidades previstas neste artigo, é o poluidor, obrigado, independentemente da existência de culpa, a indenizar ou reparar os danos causados ao meio ambiente, afetados por sua atividade (LARCHER, 2012, p. 7).

E assim o é porque o legislador nacional, em termos de responsabilidade civil por danos ambientais, adotou a teoria do risco integral, pela qual toda empresa possui riscos inerentes à sua atividade, devendo, por essa razão, assumir o dever de indenizar os prejuízos ao meio ambiente decorrentes de sua operação.

Nesse horizonte, também a responsabilidade civil por dano ambiental ganha relevo, na medida em que, pela sua natureza, os riscos que caracterizam a sociedade pós-industrial têm direta relação com o meio ambiente, considerando que, além de derivarem de novas atividades, a exemplo da energia nuclear e da produção química e biotecnológica avançada (BECK, 2002), são riscos dotados de grande magnitude e alcance global, que "subvertem as bases da lógica dos riscos então reinante e que, partindo de decisões humanas, apresentam a possibilidade de destruição de toda a vida do planeta" (BAHIA, 2015, p. 55).

Por força da teoria do risco integral da atividade, adotada pelo legislador nacional, fato natural ou de força maior não têm o condão de afastar a responsabilidade do empreendedor, pois “[...] o causador do dano é responsável em virtude de sua atividade potencialmente poluidora, sujeitando-se ao seu ônus, independente do exame da subjetividade do agente”. (LEITE, 2003, p. 201).

No sistema do Código Civil Brasileiro, para a caracterização do motivo de força maior, requerse a ocorrência de três fatores: imprevisibilidade, irresistibilidade e exterioridade. Sob esse prisma, se o dano foi causado somente por força da natureza, sem a concorrência do agente, fica excluído o nexo 
causal entre o dano e a ação ou omissão do agente, ficando afastada a responsabilidade civil (LARCHER, 2012).

\section{O caso da Samarco}

Fundada em 1977, a Samarco é uma empresa brasileira de mineração, de capital fechado, controlada em partes iguais por dois acionistas: BHP Billiton Brasil Ltda. e Vale S.A. O principal produto são pelotas de minério de ferro comercializas para a indústria siderúrgica mundial. Exportam para 19 países das Américas, Oriente Médio, Ásia e Europa. Possui três concentradores instalados na unidade de Germano, em Minas Gerais, que beneficiam o minério e aumentam o seu teor de ferro. A estrutura conta ainda com quatro usinas de pelotização na unidade de Ubu, no município de Anchieta, no Espírito Santo. As duas unidades industriais são interligadas por três minerodutos, com quase 400 quilômetros de extensão cada, que transportam a polpa de minério de ferro entre os dois estados, sendo pioneiros nesse tipo de transporte. (SAMARCO, online)

O recente episódio ocorrido em Mariana-MG, envolvendo o rompimento de barragem da sociedade anônima Samarco Mineração S.A., é um desastre ambiental de grandes proporções, despertando a atenção para a temática do dano ambiental e de sua responsabilização e reparação. Vivese, atualmente, em uma sociedade de risco, em que os estes se caracterizam por serem abstratos, globais, imprevisíveis e pouco conhecidos pela ciência (PRIMO; BELCHIOR, 2016, p. 10).

Em 05 novembro de 2015, a barragem de Fundão, de propriedade da Sociedade Anônima Samarco Mineração S.A., localizada no Município de Mariana, em Minas Gerais, foi alvo de um rompimento, que acarretou a erosão da barragem de Santarém e resultou no derramamento de cerca de 50 milhões de metros cúbicos de rejeitos de mineração no vale do rio Doce.

De acordo com a Samarco, em função do rompimento da barragem de Fundão, um volume de aproximadamente 32 milhões de $\mathrm{m}^{3}$ de rejeitos provenientes da atividade minerária - volume parcial do total de 56 milhões de $\mathrm{m}^{3}$ que estavam armazenados - vazou para fora da área da empresa (SAMARCO). O material atingiu um rio próximo às operações da Samarco (Gualaxo do Norte), percorreu o seu leito, desaguou no Rio Doce e chegou ao mar em 22 de novembro de 2015. O percurso da pluma de turbidez até chegar à foz do Rio Doce, no encontro com o Oceano Atlântico, impactou diversos municípios nos Estados de Minas Gerais e Espírito Santo, ao longo de 650 quilômetros.

Página 257 Caderno de Ciências Sociais Aplicadas, Vitória da Conquista/BA, vol. 14, n 24, ano 14, p. 247-265, jul/dez 2017. 
A lama formada por esses rejeitos, segundo dados do Alto Comissariado das Nações Unidas para Direitos Humanos, que contrariam o alegado pela Companhia mineradora referida, era composta de resíduos de minério de ferro, contendo altos níveis de metais pesados e outros produtos químicos tóxicos, e atingiu diretamente 663 quilômetros de corpos hídricos, carreando resíduos até a foz do rio Doce, no oceano Atlântico, já no Estado do Espírito Santo, o que qualifica o episódio como o maior acidente da História, com barragens de rejeitos (AZEVEDO, 2016) e, segundo alguns, o maior desastre ambiental já ocorrido no Brasil.

Laudo técnico preliminar divulgado pelo Instituto Brasileiro do Meio Ambiente e dos Recursos Naturais Renováveis (IBAMA, 2015), em dezembro de 2015, constatou que o desastre resultou, dentre outras coisas, na morte de trabalhadores da Samarco e de moradores das comunidades afetadas; no desalojamento de populações; na devastação de localidades, com a perda de estruturas públicas e privadas; na destruição de 1.469 hectares de vegetação, incluindo Áreas de Preservação Permanente (APP); na mortandade de biodiversidade aquática e fauna terrestre; na perda e na fragmentação de habitats; na interrupção da pesca por tempo indeterminado; na interrupção do turismo; na alteração dos padrões de qualidade da água doce, salobra e salgada; na interrupção do abastecimento de água e na dificuldade de geração de energia elétrica pelas hidrelétricas atingidas (IBAMA, 2015).

Para Roger Lima de Moura, delegado da Polícia Federal de Minas Gerais, a Samarco assumiu o risco e privilegiou o lucro em detrimento da segurança. Ele afirma que a PF conseguiu apreender documentos que comprovam conversas entre área técnica e a direção da mineradora, comunicando sobre problemas. Segundo o delegado, o risco que corria a comunidade de Bento Rodrigues teria sido omitido do licenciamento. Acresce Moura (2016) que, verbis, “Tem nos autos que eles pensaram em comprar Bento Rodrigues".

Ainda de acordo com o portal de notícias, a empresa não tinha conhecimento da iminência do rompimento, mas estava ciente de diversas falhas que a estrutura apresentava.

Segundo o delegado da Polícia Federal de Minas Gerais Roger Lima de Moura, ipsis litteris:

"Os crimes que já estavam sendo apurados anteriormente foram confirmados e agora com as provas mais robustas de que a barragem de Fundão estava sendo utilizada de uma forma inadequada, acima da sua capacidade. Ela apresentava problemas desde sua construção, com utilização de material de baixa qualidade. Depois, modificações sem projeto, problemas de drenagem, problemas com recuo da ombreira esquerda do eixo da barragem, em que se invadiu uma área que não era firme o suficiente".

Página 258 Caderno de Ciências Sociais Aplicadas, Vitória da Conquista/BA, vol. 14, nº 24, ano 14, p. 247-265, jul/dez 2017. 
Moura destacou, igualmente, que o rompimento teria começado na área desta ombreira.

Ainda segundo o inquérito da PF, houve também redução do orçamento na área de geotécnica que seria responsável pelo controle da barragem. Ele aponta que, de 2012 a 2015, a queda foi de 29\% e que a previsão para 2016 era de redução de 38\%. Por outro lado, conforme o delegado, foi constatado aumento de investimento na produção. Ele também afirmou que o lançamento de lama por parte da Vale contribuiu para o desastre ambiental. Segundo Moura, em um primeiro momento, a empresa negou o despejo de rejeito, mas acabou assumindo, apesar de informar um valor menor do que o apurado (MOURA, 2016).

A Vale assumiu isso, como se lançasse 5\% de despejo de rejeito, porém o que foi constatado é que o percentual é muito maior. Chegava, do total de lama que era lançado no Complexo de Germano, o que pertencia à Vale era $27 \%$. E esse $27 \%$ contribuiu para que o rejeito de lama se aproximasse do rejeito arenoso, que é uma das causas de ocorrer a liquefação, depois que fez com que a barragem rompesse. A Polícia Federal também apurou os danos causados à fauna, à flora e ao Rio Doce. Segundo o inquérito, foram devastados 1.176,44 hectares de mata, sendo 774,23 hectares de áreas de preservação permanente (MOURA, 2016).

De contrapartida, em sua defesa, a Samarco e a Vale, responsáveis pela tragédia, embora neguem dolo, afirmou (a primeira), que sempre operou com altos padrões de segurança em todos os seus processos. A empresa disse ainda que "mantém todos os seus monitoramentos em linha com as exigências legais e com as melhores práticas do mercado internacional de mineração". A Vale repudiou o indiciamento de um funcionário da empresa e alegou, por meio de nota, que ele não teve qualquer responsabilidade pela gestão de Fundão. A mineradora também comentou sobre as informações da polícia relativas ao lançamento de rejeito na barragem.

Sobre o comunicado da ONU, conforme informou o Portal G1 (2016), a mineradora declarou que tem implementado dezenas de programas socioambientais e econômicos. A Samarco também afirmou que tem se empenhado em reparar e compensar os danos, de acordo com normas internacionais, e para atender as expectativas da sociedade.

A Fundação Renova, criada pela Samarco, anunciou, na sexta-feira (4 de novembro/2016), o início do Programa de Indenização Mediada (PIM), em Colatina, Noroeste do Espírito Santo. O objetivo é ressarcir os atingidos pelos danos provocados pelo rompimento da barragem de Fundão, em Mariana. O PIM é aberto a pessoas, famílias, micro e pequenas empresas que tenham sofrido perdas

Página 259 Caderno de Ciências Sociais Aplicadas, Vitória da Conquista/BA, vol. 14, nº 24, ano 14, p. 247-265, jul/dez 2017. 
materiais ou em atividades econômicas, em consequência direta e imediata do rompimento, com adesão voluntária e gratuita (PORTAL G1, 2016).

Desde então, diversas medidas extrajudiciais e judiciais são adotadas por autoridades federais e estaduais, visando a responsabilizar a Samarco, que é controlada por duas grandes sociedades empresárias, a BHP Billiton Brasil LTDA e a Vale S.A., bem como reparar os prejuízos causados pelo rompimento da barragem de Fundão, a exemplo da assinatura de Termo de Compromisso Preliminar entre a Companhia, o Ministério Público de Minas Gerais e o Ministério Público Federal, com a prestação de caução para tutela ambiental emergencial; da instauração de inquéritos civis e criminais e do ajuizamento de ações civis públicas (PRIMO; BELCHIOR, 2016, p. 11).

Em razão da magnitude e da repercussão do episódio, vários aspectos jurídicos relativos aos danos ambientais provocados pela catástrofe em tablado vieram à tona e passaram a ser abordados pela mídia, frequentemente de maneira superficial e a técnica, a exemplo da possibilidade ou não de reparação integral dos prejuízos; da existência ou não de culpa por parte da Samarco e da possibilidade ou não de invocação, pela Samarco, de excludentes do nexo de causalidade, como a força maior e o caso fortuito, na tentativa de qualificar o ocorrido como um acidente, eximindo-a da responsabilidade pelos danos provocados (PRIMO; BELCHIOR, 2016, p. 12).

\section{A Samarco e os desdobramentos da reponsabilidade civil}

Em face do contínuo crescimento econômico e da preocupação de conservação e proteção ambiental, as atividades extrativistas têm sido foco de atenção em todo mundo, principalmente quando se lembra do trágico rompimento da Barragem Fundão, da empresa Samarco, localizada em Mariana (MG), que levou a óbito 19 pessoas (sendo que a 20ª (vigésima) vítima, um funcionário da Samarco, nunca foi encontrada) e devastou do mapa da localidade o povoado de Bento Rodrigues, que foi totalmente coberto pela lama derramada pelo rompimento da barragem, destruindo casas, sítios, escolas, igrejas e tudo mais que havia no local.

A poluição dos rios próximos, principalmente do Rio Doce, o mais prejudicado, onde a vida aquática foi completamente dizimada, associado ao derramamento afim no mar, chegando ao Estado do Espírito Santo, causa preocupação, revolta da população atingida e permanente discussão sobre como, e até quando, essa situação de poluição, destruição e descaso com a vida ali existente ainda serão tratadas com tamanho descaso.

Página 260 Caderno de Ciências Sociais Aplicadas, Vitória da Conquista/BA, vol. 14, n 24, ano 14, p. 247-265, jul/dez 2017. 


\section{- Cadernos de Ciênclas Socials ApLICADAS}

Tinoco e Robles (2006) frizam que a poluição e os impactos ambientais de toda ordem prejudicam a comunidade, gerando problemas de saúde para os cidadãos e gastos crescentes para o poder público, que, no caso específico da Samarco, até agora, um ano depois do rompimento da barragem, continuam como ficaram, pois as indenizações aos moradores do local não foram pagas e a restauração do meio ambiente, com ações pontuadas, sequer foi iniciada.

FIGURA 1: Barragem de Fundão, administrada pela Samarco

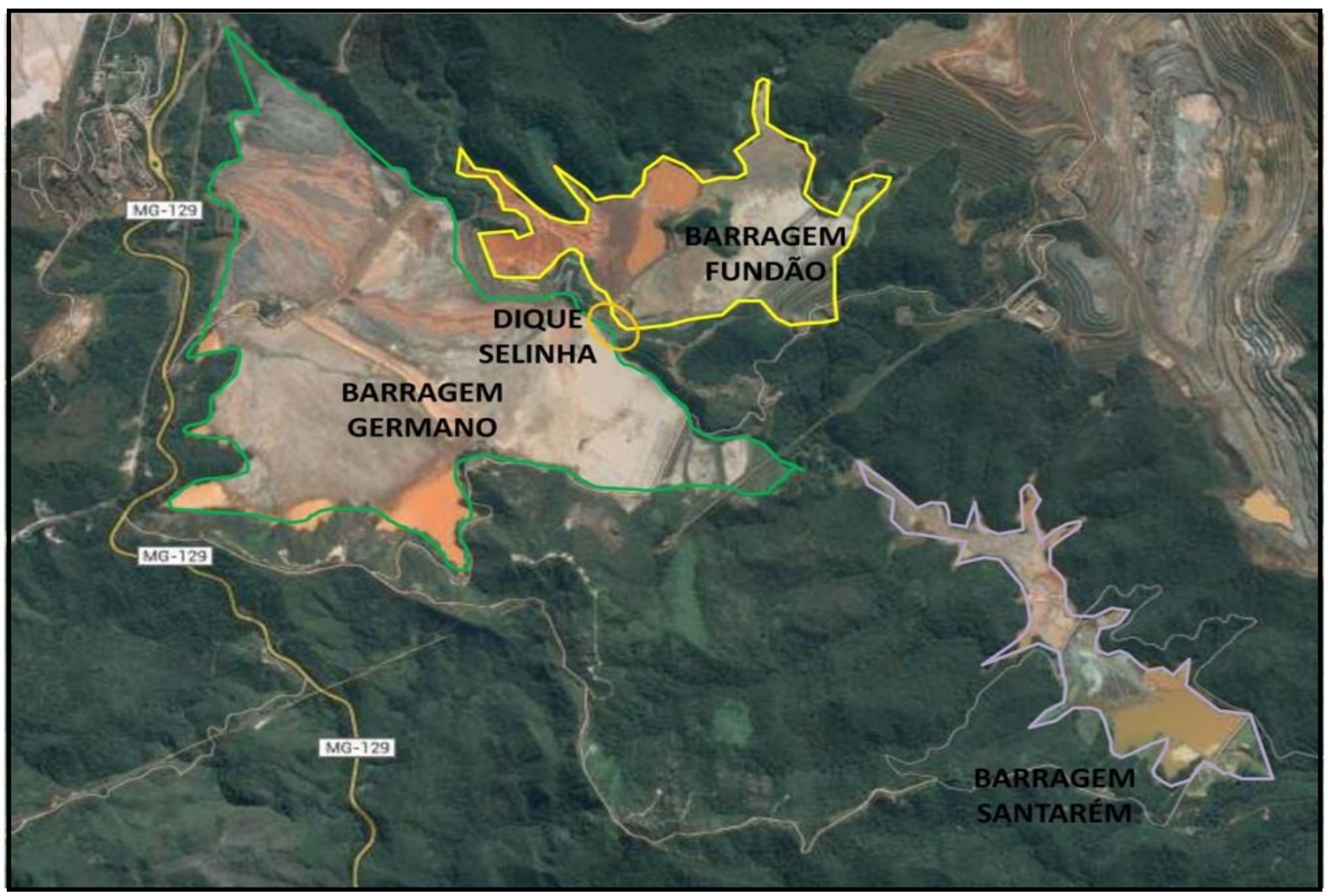

Fonte: Divulgação/Samarco, (2015). Disponível em: <http://g1.globo.com/minas-gerais/desastre-ambiental-emmariana/noticia/2015/12/mp-apura-se-obras-foram-iniciadas-antes-de-licenciamento-em-fundao.html $>$

Conforme relato de Gonçalves, Fusco e Vespa (2015), em edição digital da Revista Veja, além da tragédia humana, o desastre em Mariana teve impacto ambiental difícil de avaliar. O IBAMA já aplicou multas preliminares no valor de 250 milhões de reais à Samarco. A mineradora deverá arcar ainda com a indenização às pessoas afetadas e com os custos de reconstrução da região atingida. A Justiça de Minas Gerais bloqueou 300 milhões de reais da conta da Samarco para garantir esses pagamentos.

Página 261 Caderno de Ciências Sociais Aplicadas, Vitória da Conquista/BA, vol. 14, nº 24, ano 14, p. 247-265, jul/dez 2017. 
Assim, de acordo com Larcher (2012), o agente poluidor deve responder integralmente por todos os riscos inerentes à sua atividade, pois a teoria do risco integral pelo dano ambiental fulcra-se no princípio da equidade, uma vez que aquele que lucra com uma atividade deve igualmente responder pelo risco ou danos dela decorrente. Não se pode olvidar que o sistema de responsabilidade civil ambiental assenta-se em princípios tais como o do poluidor-pagador, da precaução e da reparação integral do dano ambiental.

A discussão não vai ter um fim próximo, principalmente um que venha a corrigir todos os danos que a empresa causou à natureza e àquelas pessoas, completando mais de um ano e com nada de concreto, a não ser alguma ajuda de custo, oferecida às famílias diretamente atingidas, o que não é o suficiente.

Com águas poluídas, vidas dizimadas (peixes e aves), territórios extintos e inabitáveis, Mariana vive seu drama do dia a dia sem muitas perspectivas, pois as empresas responsáveis pelo ocorrido, após um ano, ainda não agiram no sentido de recuperar o rio prejudicado, nem as cidades atingidas pelos rejeitos da barragem rompida.

De acordo com Moura (2016), o IBAMA aplicou mais três multas à Samarco, a mineradora responsável pelo vazamento da Barragem de Fundão. Numa delas, a empresa vai ter que pagar R $\$ 500$ mil por dia, porque não adotou medidas para conter o risco ambiental antes do período chuvoso. Um comunicado da ONU (Organização das Nações Unidas) afirma que as medidas adotadas pelo governo brasileiro e pelas empresas envolvidas no desastre são insuficientes para resolver os problemas ambientais e humanos.

É possível que, com vasto debate e uma tomada enérgica de ações pontuais e objetivas na seara da plena eficácia da responsabilidade civil na mineração, a questão da tragédia de Mariana receba um ponto final.

\section{Considerações Finais}

A tragédia de Mariana (MG), assunto que alardeou e continua alardeando a mídia de massa em todo mundo, pois os danos ambientais foram graves e sem precedentes no Brasil, ainda é um problema com solução a perder de vista, embora a legislação vigente seja pertinente, salutar e aplicável nesse caso, que conta com o amparo da mesma lei para não agir em defesa, ou mesmo conserto, do estrago feito com a destruição da barragem da Samarco.

Página 262 Caderno de Ciências Sociais Aplicadas, Vitória da Conquista/BA, vol. 14, n 24, ano 14, p. 247-265, jul/dez 2017. 
Sendo atividade de extrema importância para a economia, a mineração precisa ser realizada com responsabilidade e compromisso com o meio ambiente, visto que este não vem suportando, ao longo de séculos de exploração, os impactos negativos que a extração de suas riquezas vem sofrendo.

A Samarco, empresa de grande porte, conta com um amparo jurídico forte e atuante, mostrando competência em combater a ações impetradas por associações de moradores prejudicados com o derramamento dos rejeitos, de associações ambientais, do ministério público e ações cíveis, todas visando reparos, principalmente para o meio ambiente e a comunidade local, os mais afetados.

Afiança-se, por fim, que a abordagem do presente estudo apontou os aspectos gerais da responsabilidade civil sobre o crime ambiental experimentado em Mariana (MG), inferindo que embora a Samarco afirme que tem compromisso socioambiental com a localidade onde atua e com a atividade que desempenha, vem assumindo posições, em consonância com seus gestores, que se mostram contrárias e que despertam e impulsionam o debate acerca da depreciação dos recursos ambientais, da exploração demasiada da natureza e do descaso que se tem com os seres vivos, sejam humanos ou da fauna e flora, diretamente atingidos por essa tragédia que, por anos, vai ser assunto recorrente em todos os meios conhecidos.

\section{REFERÊNCIAS}

ALVES, R. R. de M. Responsabilidade Penal Da Pessoa Jurídica Por Crimes Ambientais. 2009. 53 fls. Monografia. Curso Direito. UNIVERSIDADE DE BRASÍLIA - UnB - Faculdade de Direito. Brasília - DF, 2009. Disponível em: < http://www.fesmpdft.org.br > Acesso em: 03/11/206

AZEVEDO, Ana Lucia. Acidente em Mariana é o maior da História com barragens de rejeitos. O Globo, Rio de Janeiro, 17 nov. 2016. Disponível em: <http://oglobo.globo.com> Acesso em: 26 jan. 2016.

BAHIA, Carolina Medeiros. Juridicidade da causalidade ambiental. In: LEITE, José Rubens Morato (coord.). Manual de Direito Ambiental. São Paulo: Saraiva, 2015.

BARRETO, M. L. Mineração e desenvolvimento sustentável: desafios para o Brasil. Rio de Janeiro: CETEM/MCT, 2001.

BECK, Ulrich. La sociedad del riesgo global. Tradução de Jesús Alborés Rey. Madri: Siglo Veintiuno de España Editores, 2002.

BRASIL. Constituição da República Federativa do Brasil de 1988. Brasília, 5 de outubro de 1988. Disponível em: <http://www.planalto.gov.br > Acesso em: 10/11/2016.

Página 263 Caderno de Ciências Sociais Aplicadas, Vitória da Conquista/BA, vol. 14, n 24, ano 14, p. 247-265, jul/dez 2017. 
CAVAliERI FILHO, Sérgio. Programa de Responsabilidade Civil. São Paulo: Atlas, 2010.

COELHO, Fábio Ulhoa. Curso de Direito Civil: obrigações e responsabilidade Civil. 5 ed. São Paulo: Saraiva, 2012a.

DIAS, José de Aguiar. Da responsabilidade civil. v. 1. 9. ed. Rio de Janeiro: Forense, 1994.

FARIAS, Carlos Eugênio Gomes. Mineração e Meio Ambiente no Brasil. Relatório preparado para o CGEE. Outubro/2002. Disponível em: <http://www.mma.gov.br/ Acesso em 26/09/2016.

GERMANY, Darcy José. A Mineração No Brasil.Centro de Gestão e Estudos Estratégicos - CT Mineral: Secretaria Técnica do Fundo Setorial Mineral. Rio de Janeiro: 2002. Disponível em: $<$ https://www.finep.gov.br > Acesso em: 08/11/2016.

GONÇALVES, Carlos Roberto. Comentários ao Código Civil. Volume XI, Editora Saraiva, São Paulo, 2003.

GONÇALVES, Eduardo; FUSCO, Nicole; VESPA, Talyta. Tragédia em Mariana: para que não se Repita. 2015. Disponível em: <http://veja.abril.com.br/ Acesso em: 25/10/2016.

GUEDES, Gilse Barbosa. Mineração e Movimentos Sociais. 2015. 267 p. Dissertação (Mestrado de Ciências Sociais em Desenvolvimento, Agricultura e Sociedade). Instituto de Ciências Humanas e Sociais. Universidade Federal Rural do Rio de Janeiro, Rio de Janeiro, RJ, 2015.

GUIA DO MINERADOR. Informações Básicas. 2000. Disponível em: <http://docslide.com.br> Acesso em 26/09/2016.

IBAMA. Instituto Brasileiro do Meio Ambiente e dos Recursos Naturais Renováveis. Laudo técnico preliminar: impactos ambientais decorrentes do desastre envolvendo o rompimento da barragem de Fundão, em Mariana, Minas Gerais, nov. 2015. Disponível em: <http://www.ibama.gov.br/. Acesso em: 25 jan. 2016.

LARCHER, Marta Alves. A Responsabilidade Civil Decorrente de Acidentes Ambientais Deflagrados por Eventos da Natureza - O Caso do Rompimento da Barragem de Rejeitos em Miraí. 2012. Disponível em: <https://aplicacao. mpmg.mp.br. Acesso em 26/09/2016.

LEITE, José Rubens Morato. Dano Ambiental: do individual ao coletivo extrapatrimonial. 2. ed. rev., atual. e ampl. São Paulo: Editora Revista dos Tribunais, 2003

MOURA, Roger Lima de. PF conclui inquérito da tragédia de Mariana e indicia 8 pessoas. G1 MG, 2016. Online. Disponível em: <http://g1.globo.com/minas-gerais > Acesso em: 03/11/2016.

PERCEGONA, Caroline Gaida. Qualidade de vida e respeito ao meio ambiente Artigos sobre Políticas Públicas para Implantação. 2016.. 31 fls. Acesso em 26/09/2016.

PORTAL G1.. 2016. Disponível em: <http://g1.globo.com/jornal. Acesso em: 03/11/2016.

Página 264 Caderno de Ciências Sociais Aplicadas, Vitória da Conquista/BA, vol. 14, n 24, ano 14, p. 247-265, jul/dez 2017. 
PRIMO, Diego de Alencar Salazar; BELCHIOR, Germana Parente Neiva. A responsabilidade civil por dano ambiental e o caso Samarco: desafios à luz do paradigma da sociedade de risco e da complexidade ambiental. RJurFA7, Fortaleza, v. 13, n. 1, jan./jun. 2016. Disponível em: <http://www.egov.ufsc.br. Acesso em 26/09/2016.

ROCHA, Fernando Antônio Nogueira Galvão da. Responsabilidade Penal da Pessoa Jurídica. In: Direito Ambiental na Visão da Magistratura e do Ministério Público. Coordenadores: Jarbas Soares Júnior e Fernando Galvão. Ed. Del Rey, 2003.

RODRIGUES, Marcelo Abelha. Instituições de Direito Ambiental. V. 1. São Paulo: Max Limonad, 2002.

ROSENVALD, Nelson. As funções da responsabilidade civil: a reparação e a pena civil. 2. ed. São Paulo: Atlas, 2014.

SAKAE, Lucia Reiko. A responsabilidade penal da pessoa jurídica. Cadernos de Pós-Graduação em Direito Político e Econômico. São Paulo, v. 4, 2004. Disponível em: <http://www.mackenzie.br. Acesso em: 07/11/2016.

SAMARCO. Disponível em: < http://www.samarco.com/ Acesso em 21/10/2016.

SILVA, J. A. Direito ambiental constitucional. São Paulo: Malheiros, 1994.

SILVA, Olintho Pereira da. A Mineração em Minas Gerais: passado, presente e futuro. Geonomos. 2009. Disponível em: <http:// redeaplmineral.org.br. Acesso em: 08/11/2016.

TINOCO, J.E.P.; ROBLES, L.T. A contabilidade da gestão ambiental e sua dimensão para a transparência empresarial: estudo de caso de quatro empresas brasileiras com atuação global. RAP Rio de Janeiro. Nov./Dez. 2006. Disponível em: <http://www.scielo.br/pdf/rap/v40n6/08.pdf> Acesso em: 23/10/2016. 